\title{
Bleeding Risk in Children with Preoperative Prolonged Coagulation Tests
}

\author{
(D) Ali Ayçiçek ${ }^{1}$, (1) Aykut Saral ${ }^{2}$ \\ ${ }^{1}$ University of Health Sciences Turkey, Başakşehir Çam and Sakura City Hospital, Clinic of Pediadric Hematology \\ and Oncology, İstanbul, Turkey \\ ${ }^{2}$ Eskisehir State Hospital, Biochemisty Laboratory, Eskişehir, Turkey
}

\section{What is known on this subject?}

Repeated tests and controls are performed in mildly prolonged coagulation tests, and very essential surgical interventions are delayed.

\section{What this study adds?}

Repeated tests and checks are unnecessary in mildly prolonged coagulation tests.

\section{ABSTRACT}

Objective: Prolonged coagulation test is a common finding before surgery. This study determined the prolonged prothrombin time (PT) and/or activated partial thromboplastin time (aPTT) during the surgical preparation of pediatric patients.

Material and Methods: As a cross-sectional study, 74 children aged 0.25-17 years, who had prolonged preoperative coagulation tests, were included in the Eskişehir State Hospital Pediatric Hematology and Oncology Clinic between September 3, 2013, and September 16, 2014.

Results: The mean age of the children was $5.6 \pm 3.4$ years, wherein $60(81 \%)$ cases were male. Adenoid-tonsillar operations were planned in $46 \%$, circumcision in $43 \%$, abdominal operations in $5 \%$, and other operations in $6 \%$. A history of bleeding was found in $7(10 \%)$ of the families and $3(4 \%)$ of the cases. Previous surgery or injury was found in $24(32 \%)$ of the children and did not develop more bleeding than expected. The coagulation tests revealed 22 (30\%) patients with prolonged PT (value range: 14-35.1 s), 47 (63\%) with prolonged aPTT (value range: 37.1-129.6 s), and 5 (7\%) with both prolonged PT and aPTT. A necessary operation was performed in 47 patients who did not have a history of bleeding diathesis in the patient or family, with a normal mixed test and factor levels, and PT of $<20$ s and aPTT of $<63.3 \mathrm{~s}$. No bleeding complications were observed during or after the operation in any of these cases.

Conclusion: Our results revealed that in case of prolonged PT or aPTT values before surgery, no risk of bleeding is encountered during the surgery if a history of bleeding diathesis is not present in the patient or family and factor levels are normal.

Keywords: Child, blood coagulation tests, bleeding diathesis, perioperative period

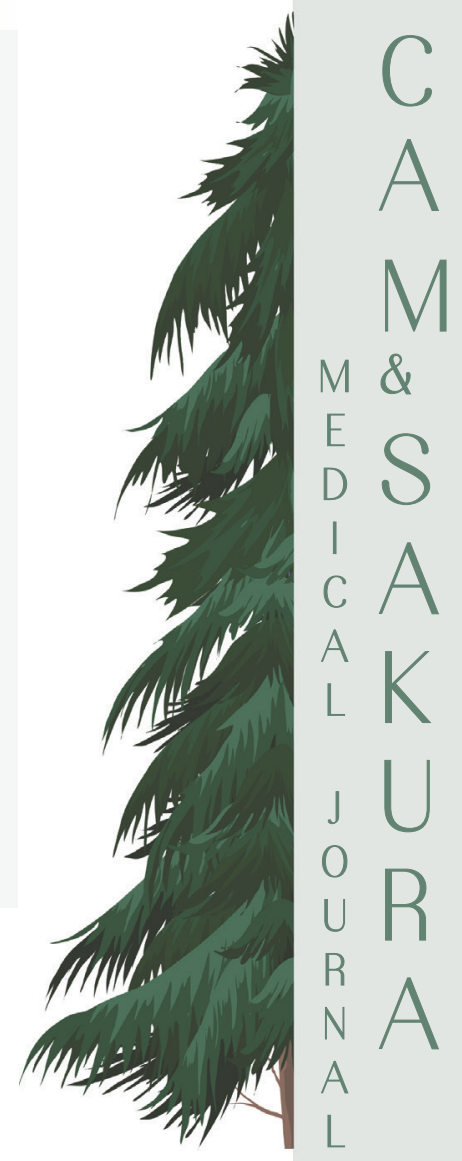

Address for Correspondence: Ali Ayçiçek MD, University of Health Sciences Turkey, Başakşehir Çam and Sakura City Hospital, Clinic of Pediadric Hematology and Oncology, İstanbul, Turkey

Phone: +90 2125122086 E-mail: ayciceka@hotmail.com0RCID ID: orcid.org/0000-0001-8951-4750

Received: 30.05.2021 Accepted: 17.06.2021

(C) Copyright 2021 by the Cam \& Sakura Medical Journal published by Galenos Publishing House. 


\section{Introduction}

The cost and the effectiveness of coagulation tests that are performed before surgical intervention is a long-debated issue $(1,2,3,4)$. Contrarily, existing habits and efforts are done to prevent possible complications, and problems arise from the delay of the planned surgery together with unnecessary time and financial loss.

Prothrombin time(PT) and activated partial thromboplastin time (aPTT) are used as hemostasis screening tests and are requested in preoperative "routine" analyzes $(4,5)$. The clinical significance of prolonged PT and/or aPTT values that have been reported, especially in patients without anticoagulant therapy and significant liver pathology, is very limited and without bleeding symptoms before and after $(6,7)$.

A limited number of articles have been published in our country on preoperative coagulation tests and evaluations that should be performed in case of prolonged results, and most of them are compiled $(8,9,10,11,12,13)$. This study compiled the cross-sectional data of cases that are referred to Eskişehir State Hospital Pediatric Hematology and Oncology Outpatient Clinic because PT and/or aPTT measurements were longer than normal and discussed these results.

\section{Material and Methods}

In this cross-sectional study, 74 pediatric patients aged 0.25-17 years, who were found with prolonged preoperative PT and/or aPTT tests, were admitted to the Eskişehir State Hospital Pediatric Hematology and Oncology Outpatient Clinic between September 3, 2013, and September 16, 2014. PT was $13.5 \mathrm{~s}$ and aPTT was $37 \mathrm{~s}$ were given as the upper limits of the coagulation laboratory of the hospital where our study was conducted, thus these values were taken as basis in the study. All results included in the study were obtained from the same coagulation laboratory. For interventional procedures, PT and aPTT that is $>1.5$ times the upper normal limit (PT of $>19 \mathrm{~s}$ and aPTT of $>55 \mathrm{~s}$ ) was determined as significant elevation and further investigations were planned (14). Age, gender, place of origin of cases, complaint upon arrival, easy bruising, delayed bleeding, nosebleeds, bleeding in other parts of the body, excessive menstrual bleeding during menstruation (the number of pads used in the first 2 days, the need to put a diaper when the bleeding increases, and total duration of menstruation), accompanying symptoms, and drug use was asked. PT and aPTT tests were performed with Greiner Vacuette ${ }^{\circledR}$ 9NC sodium citrate of 3.2\%, IL-ACL TOP 500 CTS (USA) device on the samples taken into $3 \mathrm{~mL}$ coagulation tubes. Cases with prolonged results that persisted in at least two measurements, those with a family history of bleeding diathesis, and those with prolonged results of $>50 \%$ of the upper limit in the tests were subjected to, further coagulation factors and mixture tests. The mixture test is an easy and inexpensive test that guides the involvement of factor deficiency or the presence of inhibitors with prolonged coagulation test results. Coagulation tests are based on the principle of re-running the coagulation test by mixing a sample that is within normal limits with a long sample in half. If factor deficiency is the cause, coagulation tests are normal as a result of the mixture but do not return to normal in the presence of an inhibitor. In cases where tests were significantly longer but advanced coagulation studies were normal, the operation approval was given after the informed consent of the patient's parents. Ethical approval was obtained from the Chief Physician of Eskişehir State Hospital on 22.11.2013.

\section{Statistical Analysis}

The variables were checked for homogeneity of variance using the Levene statistic. Data were presented as number, ratio, and mean \pm standard deviation (SD). Chi-square was used to compare the ratios, and a dependent sample t-test was used to compare the means. Differences were considered to be statistically significant at a $p$ value of $<0.05$. The Statistical Package for the Social Sciences version 16 for Windows (SPSS ${ }^{\circledR}$ Inc, Chicago, IL) was used for the statistical analysis program.

\section{Results}

A total of 60 (81\%) male patients, with a mean age of 5.6 $6 \pm 3.4$ years, were planned for adenoid-tonsillar operation in $46 \%$, circumcision in $43 \%$, abdominal in $5 \%$, and other operations $6 \%$. Even when circumcision operations were removed, prolonged coagulation tests were found to be significantly higher in boys than in girls $(p<0.001)$. Epistaxis was the only bleeding diathesis in the anamnesis that accounts for $3 \%$. The anamnesis for bleeding diathesis in first or second-degree relatives was $7 \%$, but none were diagnosed with bleeding disorders. Surgical intervention was previously undergone by $32 \%$ of patients and had no bleeding complications.

In cases with prolonged coagulation tests, 22 (30\%) had prolonged PT (range; 14-35.1 s), 47 (63\%) had prolonged aPTT (range; of 37.1-129.6 s), 5 (7\%) had both prolonged PT and aPTT. Tests were repeated in the same week in all of these cases. The comparison of the mean values of both parameters and international normalized ratio (INR) values before and after surgery revealed no significant difference $(p>0.05$, Table 1), and both were prolonged after the repetition. PT or aPTT was significantly longer in 5 of all cases. One patient had a 
Table 1. The first and second measurement results of patients who were approved for the operation*

\begin{tabular}{|c|c|c|c|c|c|c|}
\hline & \multicolumn{2}{|c|}{ PT (second) } & \multicolumn{2}{|c|}{ INR } & \multicolumn{2}{|c|}{ aPTT (second) } \\
\hline & First & Repeat & First & Repeat & First & Repeat \\
\hline Mean $( \pm S D)$ & $13.5 \pm 3.7$ & $12.9 \pm 2.6$ & $1.17 \pm 0.34$ & $1.11 \pm 0.18$ & $40.1 \pm 7.9$ & $41.1 \pm 7.0$ \\
\hline Shortest & 10.6 & 10 & 0.92 & 0.86 & 20.9 & 26.1 \\
\hline Longest & 35.1 & 20.2 & 3.03 & 1.74 & 62.3 & 62 \\
\hline
\end{tabular}

history of suspicious bleeding diathesis (more than 1.5 times the normal value), although aPTT was $40 \mathrm{~s}$, and 3 cases had a family history of bleeding diathesis with epistaxis (1 prolonged PT, 2 prolonged aPTT) examinations were made.

Mixture test in prolonged APTT, factor VIII, vWF, vWF R: C, and factor IX; factor VII levels were studied in patients with a prolonged PT, and factor $\mathrm{X}$ levels in those with prolonged PT. Factor VIII level was $44 \%$ in one case and factor VII level was $40 \%$ in one case. The levels of other cases were found to be within normal limits. Normal values were found in patients who underwent the mixture test, and no case had a significant length in aPTT value after $2 \mathrm{~h}$ of incubation.

A total of 65 cases had prolonged coagulation tests with normal factor level, suspected bleeding diathesis in their family, previous surgery but had no bleeding and had normal mixed tests and normal factor level with PT of $\leq 20.2 \mathrm{~s}$ or aPTT of $<63.3 \mathrm{~s}$ (normal for PT and aPTT was 1.7 times the upper limit) were approved for operation. Of these, 47 cases underwent the necessary surgical intervention, and none had bleeding complications during or after the operation.

Tests were repeated after an average of 80 days in 20 cases with significantly elevated coagulation tests and/or bleeding diathesis, and after an average of 150 days in 10, without significant difference in the mean PT and aPTT values compared to the baseline levels ( $p>0.121)$.

\section{Discussion}

Prolonged coagulation tests are a common finding in centers where pre-surgical screening is performed. In this case, the planned operation is postponed and the analyzes are repeated, as well as consultations from relevant branches, and new and advanced examinations are started. Surgery for a condition, such as adenoid vegetation, may cause treatment delays and additional complications in the patient, whereas an operation, such as circumcision, that is performed without medical necessity may cause an anxious process for the family. Contrarily, the obtained prolonged coagulation test may be the only finding of bleeding diathesis that was not diagnosed until that time, since tests, such as complete blood count, is uncommon.

The basic hemostatic system is known in detail and quickly analyzed, but the main issue is the result interpretation and follow-up in these cases (15). The benefit of routine basic coagulation tests in surgical procedures or other medical conditions is controversial $(6,16)$. These tests, which have limited sensitivity and specificity, were reported to have high false positivity, low accurate prediction and prediction levels, and high false negativity $(4,15)$. However, prolonged coagulation test results in patients with a history of bleeding before surgery were emphasized to guide the diagnosis of bleeding diathesis $(16,17,18)$. Preoperative coagulation studies in children have been investigated in adenoidectomy and/ or tonsillectomy operations, as they are the most frequently performed operations worldwide $(4,18,19,20,21)$.

Various values are accepted as limits in the literature; however, PT of $>13 \mathrm{~s}$ and aPTT of $>36 \mathrm{~s}$ are generally accepted as prolonged (6). Our study considered the normal limits of our laboratory, which are PT of $13.5 \mathrm{~s}$, aPTT of $37 \mathrm{~s}$ as the upper normal limit. In case of significant increased PT and aPTT values, the tests were repeated, and further coagulation studies were performed with values that are 1.5 times and above the upper normal limit, but no abnormal results were found. Patients and their close relatives without bleeding in cases of previous surgical intervention, circumcision, and injury, and the absence of a diagnosed bleeding disease were supportive factors in the decision to approve the operation. Our study is different from other studies as it consisted of cases that were operated on despite the prolonged coagulation test results $(7,17,21,22,23)$. A study reported that PT and/or aPTT were prolonged and surgical intervention was performed only with pro-coagulants and/or antifibrinolytics in mild factor deficiencies, and none required specific treatment due to bleeding complications (24). Since no specific factor deficiency was detected in our study, procoagulant or antifibrinolytic treatments were planned to be given in case of bleeding.

Cases with more than five nosebleeds annually are considered recurrent nosebleeds (25). In addition, if PT and 
aPTT values are determined to be prolonged, studying the FVII, FVIII, FIX, vWF: Ag, and vWF-ristocetin cofactor activity as second-line tests is recommended. Our study found no coagulation factor deficiency in any patients with epistaxis.

Karaca et al. (12) reported that 21 of 100 children who underwent preoperative coagulation screening tests (PT, INR, and aPTT) for adenotonsillectomy operation were found to have longer than normal tests, wherein $2(2 \%)$ had coagulation disorder; therefore, regardless of the cost, preoperative coagulation screening tests (PT, INR, and aPTT) were emphasized as necessary examination. However, in this study, the diagnosis of coagulation disorder was made with a value of $44.8 \%$ for factor VIII and 52\% for vWF. These levels stand as a compelling and unnecessary situation, both for making a diagnosis and for leaving patients and their owners along with the diagnosis of hemorrhagic disease. In addition, with the obtained results, concluding that these tests are necessary before the operation seems impossible.

Bhasin and Parker (4) reported that results were found to be normal in repeated tests in approximately $50 \%$ of cases. Samková et al. (24) found a similar rate when the tests were repeated in the hematology laboratory. Since those who were normal in repeated tests in our study were excluded from the study, it is impossible to present the coagulation test results in the second test within the same week. However, patients with significantly prolonged tests and/or findings in bleeding diathesis had no significant changes in the coagulation tests that were performed in the same laboratory after approximately 3 and 5 months, which suggests no significant benefit for tests before 6 months, especially in cases without bleeding symptoms.

Manning et al. (19) determined that preoperative PT and aPTT screening were not associated with surgical bleeding in 994 patients who underwent adenotonsillectomy. A 12-year retrospective study published by Wei et al. (22) found that 90 (1.93\%) of 4,662 patients who underwent tonsillectomy had bleeding, of which only 1 case was primary and the remaining 89 had secondary bleeding. Primary bleeding occurs in the first $24 \mathrm{~h}$ after tonsillectomy, which usually accompanies coagulation disorder, whereas secondary bleeding was most common on days 5-6 postoperative. The mean bleeding risk after tonsillectomy has been reported to be between $0.1 \%$ and $9.3 \%(22,23)$. The absence of bleeding observed in any of our cases shows that the risk of bleeding is not different from the others in cases of a certain prolonged level in coagulation tests in patients without bleeding diathesis findings in the anamnesis and examination. A study supporting our finding reported that a higher probability of bleeding after surgery was associated with the standard medical questionnaire, not with abnormal coagulation tests (26).

\section{Conclusion}

Prolonged PT and aPTT values before surgery of up to 1.5 times, no diagnosis of bleeding diathesis in the child or family, and result returns to normal with mixed tests, then bleeding will not occur during and after the operation. We concluded that repeated tests and to test renewed before 3 months is not necessary to check for normalization. However, larger studies are needed on this subject.

\section{Ethics}

Ethics Committee Approval: Ethical approval was obtained from the Chief Physician of Eskişehir State Hospital on 22.11.2013.

Informed Consent: Patient consent was obtained.

Peer-review: Externally and internally peer-reviewed.

\section{Authorship Contributions}

Concept: A.A., Design: A.A., Data Collection or Processing: A.A., A.S., Analysis or Interpretation: A.A., Literature Search: A.A., Writing: A.A.

Conflict of Interest: No conflict of interest was declared by the authors.

Financial Disclosure: The authors declared that this study received no financial support. 


\section{REFERENCES}

1. Silver D. What routine preoperative tests for bleeding tendencies? JAMA 1976;236:2547.

2. Eisenberg JM, Clarke JR, Sussman SA. Prothrombin and partial thromboplastin times as preoperative screening tests. Arch Surg 1982;117:48-51.

3. Segal JB, Dzik WH; Transfusion Medicine/Hemostasis Clinical Trials Network. Paucity of studies to support that abnormal coagulation test results predict bleeding in the setting of invasive procedures: an evidence-based review. Transfusion 2005;45:1413-1425.

4. Bhasin N, Parker RI. Diagnostic outcome of preoperative coagulation testing in children. Pediatr Hematol Oncol 2014;31:458-466.

5. Kamal AH, Tefferi A, Pruthi RK. How to interpret and pursue an abnormal prothrombin time, activated partial thromboplastin time, and bleeding time in adults. Mayo Clin Proc 2007;82:864-873.

6. Chee YL, Greaves M. Role of coagulation testing in predicting bleeding risk. Hematol J 2003;4:373-378.

7. Levy JH, Szlam F, Wolberg AS, Winkler A. Clinical use of the activated partial thromboplastin time and prothrombin time for screening: a review of the literature and current guidelines for testing. Clin Lab Med 2014;34:453-477.

8. Özatlı D. Perioperatif hemostaz değerlendirilmesi. Türk Hematoloji Derneği-Temel Hemostaz Tromboz Kursu 2007;64-67. Available from: www.thd.org.tr/thdData/userfiles/file/2007thtk_12.pdf

9. Beyan C. Anestezi hazırlığında hematolojik problemler. www gata.edu.tr/wpcg/images/.../PreopHematolojikDegerlendirme. ppt https://dokumen.tips/documents/anestezi-hazirligindahematolojik-problemler.html

10. Öngören Ș. Preoperatif hemostaz değerlendirmesi: antikoagülan kullananlarda perioperatif yaklașım. IU Cerrahpașa Tıp Fakültesi sürekli Tıp Eğitimi Etkinlikleri Sempozyum Dizisi 2003;36:101-132.

11. Demir M, Tekgündüz E. Preoperative hemostatic evaluation: scientific letter. Turkiye Klinikleri J Med Sci 2008;28:361-368.

12. Karaca S, Hanege FM, Özdamar Oi, Kalcıoğlu MT. Is coagulation screening tests needed before adenotonsillectomy? Bozok Med J 2014;1:1-5

13. Atamer T. Preoperatif hematolojik değerlendirme. İst. Tıp Fak. Mecmuası 2003;66:199-204.

14. Özdemir GN, Apak H. Basic transfusion management in children. Turk Arch Ped 2009;(Suppl 44):19-23.
15. Mann KG. Biochemistry and physiology of blood coagulation. Thromb Haemost 1999;82:165-174.

16. Alzahrani A, Othman N, Bin-Ali $\mathrm{T}$, et al. Routine preoperative coagulation tests in children undergoing elective surgery or invasive procedures: are they still necessary? Clin Med Insights Blood Disord 2019;12:1179545X18821158.

17. Licameli GR, Jones DT, Santosuosso J, Lapp C, Brugnara C, Kenna $M A$. Use of a preoperative bleeding questionnaire in pediatric patients who undergo adenotonsillectomy. Otolaryngol Head Neck Surg 2008;139:546-550.

18. Howells RC 2nd, Wax MK, Ramadan HH. Value of preoperative prothrombin time/partial thromboplastin time as a predictor of postoperative hemorrhage in pediatric patients undergoing tonsillectomy. Otolaryngol Head Neck Surg 1997;117:628-632.

19. Manning SC, Beste D, McBride T, Goldberg A. An assessment of preoperative coagulation screening for tonsillectomy and adenoidectomy. Int J Pediatr Otorhinolaryngol 1987;13:237-244.

20. Shaw PH, Reynolds S, Gunawardena S, Krishnamurti L, Ritchey AK. The prevalence of bleeding disorders among healthy pediatric patients with abnormal preprocedural coagulation studies. J Pediatr Hematol Oncol 2008;30:135-141.

21. Close HL, Kryzer TC, Nowlin JH, Alving BM. Hemostatic assessment of patients before tonsillectomy: a prospective study. Otolaryngol Head Neck Surg 1994;111:733-738.

22. Wei JL, Beatty CW, Gustafson RO. Evaluation of posttonsillectomy hemorrhage and risk factors. Otolaryngol Head Neck Surg 2000;123:229-235.

23. Elbistanlı MS, Elbistanlı \$̧, Kumral TL, Açıkalın RM. Evaluation of patients with post-tonsillectomy bleeding in a second-degree state hospital our patients with post-tonsillectomy bleeding. Haseki Tıp Bülteni 2013;51:1-3.

24. Samková A, Blatný J, Fiamoli V, Dulíček P, Pařízková E. Significance and causes of abnormal preoperative coagulation test results in children. Haemophilia 2012;18:e297-301.

25. Asma M, Çulha VK, Şaylı TR. The causes of epistaxis in children. Turkhis J Pediatr Dis 2009;3:5-9.

26. Masalha M, DeRowe A, Mazzawi S, et al. Coagulation tests or standardized questionnaire, which is better as a predictor of bleeding? A prospective study among children before tonsillectomy and/or adenoidectomy. BMC Res Notes 2020;13:175. 